\title{
Association of genetic variations in miR-146a rs2910164 and miR-149 rs11614913 with the development of classic Kaposi sarcoma
}

\author{
H. Yang1,2, Q.L. Lu ${ }^{3}$, X.J. Wu ${ }^{3}$, H.Y. Ma ${ }^{2}$,Y.Y. Qu ${ }^{3}$, D.Z.Zhang ${ }^{3}$ and X.M. Pu ${ }^{3}$ \\ ${ }^{1}$ Department of Dermatology and Venereology, Anhui Medical University, \\ Hefei, China \\ ${ }^{2}$ North Branch of People's Hospital of Xinjiang Uygur Autonomous Region, \\ Urumqi, China \\ ${ }^{3}$ Department of Dermatology and Venereology, \\ People's Hospital of Xinjiang Uygur Autonomous Region, Urumqi, China
}

Corresponding author: X.M. Pu

E-mail: xiongmingpuuar@163.com

Genet. Mol. Res. 15 (4): gmr15048855

Received June 6, 2016

Accepted September 16, 2016

Published November 3, 2016

DOI http://dx.doi.org/10.4238/gmr15048855

Copyright (C) 2016 The Authors. This is an open-access article distributed under the terms of the Creative Commons Attribution ShareAlike (CC BY-SA) 4.0 License.

ABSTRACT. Classic Kaposi sarcoma is a type of vascular proliferative
inflammatory disease. Previous studies have reported significant
associations between microRNAs expression and the development of
classic Kaposi sarcoma. Here, we conducted a case-control study to
investigate the association between miR-146a and miR-149 genetic
polymorphisms and risk of classic Kaposi sarcoma in a Chinese
population. Both classic Kaposi sarcoma patients and healthy controls
were recruited between December 2013 and October 2015 . Genotyping
of miR-146a and miR-149 was performed by polymerase chain
reaction-coupled with restriction fragment length polymorphism.
Results showed that the GG genotype of miR-146a was associated with

Genetics and Molecular Research 15 (4): gmr15048855 
increased risk to classic Kaposi sarcoma $(\mathrm{OR}=6.00,95 \% \mathrm{CI}=1.19$ 30.12), as compared with the CC genotype. In the recessive model, we found that the GG genotype carried a 4.55-fold increased risk to classic Kaposi sarcoma as compared with the $\mathrm{CC}+\mathrm{CG}$ genotype $(\mathrm{OR}=2.06$, $95 \% \mathrm{CI}=1.04-20.29)$. In conclusion, our study demonstrated that miR146a, but not miR-149 polymorphism, is associated with risk to classic Kaposi sarcoma in the Chinese population.

Key words: Classic Kaposi sarcoma; miR-146a; miR-149; Polymorphism

\section{INTRODUCTION}

Classic Kaposi sarcoma, also known as multiple idiopathic hemorrhagic sarcoma, is a type of vascular proliferative inflammatory disease (Friedman-Birnbaum et al., 1993). This disease occurs mostly in central European Jews, Polish, Russians, and Italians (Laresche et al., 2014; Ouyang et al., 2014; Stiller et al., 2014; Wu et al., 2015). It has been estimated that morbidity due to classic Kaposi sarcoma is $2.07 / 100,000$ in males and 0.75/100,000 in females (Guttman-Yassky et al., 2003). The pathophysiology of Kaposi sarcoma is not well understood, and previous epidemiologic studies have reported that its development is associated with many factors such as ethnicity, gender, and environment factors. However, not all individuals with such risk factors develop this disease, suggesting that genetic influence may also contribute to its pathogenesis. In support of this, previous genetic studies have indicated that heritable factors such as interleukin- 6 and interleukin- 8 contribute to the development of classic Kaposi sarcoma (van der Kuyl et al., 2004; Gazouli et al., 2004).

miRNAs are non-coding small RNAs that are typically 18-25 nucleotides in length, and regulate the expression of $30 \%$ of human proteins. They bind to post-transcriptional mRNAs, and act to suppress protein translation or degrade target mRNAs. It has been reported that approximately 9500 miRNAs contribute to cell growth, differentiation, and cell cycle regulation (Macfarlane and Murphy, 2010). Kaposi sarcoma occurs when cellular factors promote tumor development in the vascular endothelial cells and the periderm (Gessain and Duprez, 2005). Previous studies have reported significant associations between microRNA expression and development of classic Kaposi sarcoma in a Chinese population (Wu et al., 2015). In addition, miR-146a rs2910164 and miR-149 rs11614913 have also been associated with several kinds of cancers. However, their associations with risk to classic Kaposi sarcoma have not yet been investigated. Therefore, we performed a case-control study to examine the association between miR-146a rs2910164 and miR-149 rs11614913 genetic polymorphisms and risk of classic Kaposi sarcoma in a Chinese population.

\section{MATERIAL AND METHODS}

\section{Subjects}

A hospital-based case-control design was used in this study. Between December 2013 and October 2015, 30 classic Kaposi sarcoma patients were recruited from the North Branch of People's Hospital of Xinjiang Uygur Autonomous Region and People's Hospital of Xinjiang Uygur Autonomous Region. Disease was confirmed histologically via pathological

Genetics and Molecular Research 15 (4): gmr15048855 
sections in all patients. None of the subjects received any form of anti-cancer therapy prior to enrollment into our study. Patients with any history of cancers and serious end-stage liver or kidney diseases were excluded from this study.

At the same time, 96 healthy controls were recruited from outpatient clinics and health examination centers in the North Branch of People's Hospital of Xinjiang Uygur Autonomous Region and People's Hospital of Xinjiang Uygur Autonomous Region. All control subjects were confirmed to be free of cancers and serious end-stage liver or kidney diseases.

Demographic data of all participants were collected from medical records and selfdesigned questionnaires, which included information such as age, gender, family history of cancer, pathological types, and disease stages. Written informed consent was given by all subjects prior to study participation. Approval was also obtained from the Ethics Committee of the North Branch of People's Hospital of Xinjiang Uygur Autonomous Region and People's Hospital of Xinjiang Uygur Autonomous Region.

\section{Genotyping analysis}

For total genomic DNA extraction, blood samples were collected from all participants in EDTA-containing tubes shortly before treatment. Blood samples were stored at $-20^{\circ} \mathrm{C}$ in vacuum tubes containing 5\% EDTA. Genomic DNA was extracted with the DNA Blood Mini Kit (Tiangen Biotech, Beijing, China). Genotyping of the miR-146a rs2910164 and miR-149 rs11614913 loci was performed by PCR-RFLP. The forward and reverse primer sequences of miR-146a were 5'-CTGGACTGCAAGGAGGGGTCTT-3' and 5'-GTCCTCAAGCCCACGATGACAG-3', respectively. The forward and reverse primers of miR-149 were 5'-CCACCCAGCAACCCAAAGTCTAC-3' and 5'-CCTCGACGAAAACCGA CTGATG-3', respectively. Amplicons of miR-146a rs2910164 and miR-149 rs11614913 were digested by the restriction enzymes $S a c \mathrm{I}$ and $P v u \mathrm{II}$, respectively. The cycling conditions were as follows: $95^{\circ} \mathrm{C}$ for $2 \mathrm{~min} ; 35$ cycles of $94^{\circ} \mathrm{C}$ for $20 \mathrm{~s}, 59^{\circ} \mathrm{C}$ for $30 \mathrm{~s}, 72^{\circ} \mathrm{C}$ for $90 \mathrm{~s}$; and a final extension at $72^{\circ} \mathrm{C}$ for $2 \mathrm{~min}$. The PCR products were stored at $4^{\circ} \mathrm{C}$, and were later run on agarose gels. DNA bands were observed under ultraviolet light.

\section{Statistical analysis}

Genotype and allele frequencies were calculated by the gene-counting method. HardyWeinberg equilibrium (HWE) was calculated by Pearson's chi-squared test. Multivariable logistic regression analysis was performed to evaluate the association between miR-146a rs2910164 and miR-149 rs11614913 genetic polymorphisms and risk of classic Kaposi sarcoma; results are reported by odds ratios (ORs) and 95\% confidence intervals (95\%CIs). Statistical analysis was carried out using the SPSS Statistics software for Windows, Version 17.0. (SPSS, Inc., Chicago, IL, USA). P $<0.05$ was considered statistically significant.

\section{RESULTS}

No significant difference was found between classic Kaposi sarcoma patients and control subjects in terms of age $\left(\chi^{2}=0.18, \mathrm{P}=0.67\right)$, gender $\left(\chi^{2}=0.39, \mathrm{P}=0.53\right)$, and family history of cancer $\left(\chi^{2}=0.32, \mathrm{P}=0.58\right)$. Of the 30 patients with classic Kaposi sarcoma, $7(23.33 \%)$ subjects were at patch stage, $11(36.67 \%)$ cases were at plaque stage, and 12

Genetics and Molecular Research 15 (4): gmr15048855 
$(40.00 \%)$ cases were at nodule stage (Table 1). Disease progression was $<6$ months in 11 $(36.67 \%)$ patients, and $>6$ months in $19(63.33 \%)$ patients.

\section{Table 1. Demographic characteristics of all study subjects.}

\begin{tabular}{|c|c|c|c|c|c|c|}
\hline Variables & Patients $\mathrm{N}=30$ & $\%$ & Controls $\mathrm{N}=96$ & $\%$ & $\chi^{2}$ & $\mathrm{P}$ value \\
\hline \multicolumn{7}{|l|}{ Age, years } \\
\hline$<60$ & 9 & 30.00 & 25 & 26.5 & & \\
\hline$\geq 60$ & 21 & 70.00 & 71 & 73.5 & 0.18 & 0.67 \\
\hline \multicolumn{7}{|l|}{ Gender } \\
\hline Male & 23 & 76.67 & 68 & 71.3 & & \\
\hline Female & 7 & 23.33 & 28 & 28.7 & 0.39 & 0.53 \\
\hline \multicolumn{7}{|c|}{ Family history of cancer } \\
\hline No & 28 & 93.33 & 92 & 96.1 & & \\
\hline Yes & 2 & 6.67 & 4 & 3.9 & 0.32 & 0.58 \\
\hline \multicolumn{7}{|c|}{ Pathological types } \\
\hline Patch stage & 7 & 23.33 & & & & \\
\hline Plaque stage & 11 & 36.67 & & & & \\
\hline Nodule stage & 12 & 40.00 & & & & \\
\hline \multicolumn{7}{|c|}{ Process of diseases } \\
\hline$<6$ months & 11 & 36.67 & & & & \\
\hline$\geq 6$ months & 19 & 63.33 & & & & \\
\hline
\end{tabular}

Genotype distributions of miR-146a rs2910164 and miR-149 rs11614913 are shown in Table 2. As indicated by chi-squared tests, we observed a significant difference in the genotype distributions of miR-146a between classic Kaposi sarcoma patients and control subjects $\left(\chi^{2}\right.$ $=7.27, \mathrm{P}=0.026)$. However, no such association was found in miR-149 between the two groups $\left(\chi^{2}=0.17, \mathrm{P}=0.92\right)$. The genotype distributions of miR-146a rs2910164 and miR-149 rs11614913 in the control population were all under HWE.

Table 2. Genetic distribution of miR-146a rs2910164 and miR-149 rs11614913 in classic Kaposi sarcoma patients and control subjects.

\begin{tabular}{|c|c|c|c|c|c|c|c|c|}
\hline Variables & Patients $\mathrm{N}=30$ & $\%$ & Controls $\mathrm{N}=96$ & $\%$ & $\chi^{2}$ & $P$ value & $\chi^{2}$ for HWE & $P$ value \\
\hline \multicolumn{9}{|l|}{ miR-146a } \\
\hline $\mathrm{CC}$ & 9 & 30.00 & 45 & 46.88 & & & & \\
\hline CG & 15 & 50.00 & 46 & 47.92 & & & & \\
\hline GG & 6 & 20.00 & 5 & 5.21 & 7.27 & 0.026 & 2.45 & 0.12 \\
\hline \multicolumn{9}{|l|}{ miR-149 } \\
\hline TT & 11 & 36.67 & 40 & 41.67 & & & & \\
\hline $\mathrm{TC}$ & 16 & 53.33 & 49 & 51.04 & & & & \\
\hline $\mathrm{CC}$ & 3 & 10.00 & 9 & 9.38 & 0.17 & 0.92 & 1.21 & 0.27 \\
\hline
\end{tabular}

Using logistic regression analysis, we demonstrated that the GG genotype of miR146a rs2910164 genetic polymorphism was associated with increased risk to classic Kaposi sarcoma $(\mathrm{OR}=6.00,95 \% \mathrm{CI}=1.19-30.12)$, as compared with the $\mathrm{CC}$ genotype (Table 3$)$. In the recessive model, results showed that the GG genotype carried a 4.55 -fold increase in risk to classic Kaposi sarcoma as compared with the $\mathrm{CC}+\mathrm{CG}$ genotype $(\mathrm{OR}=2.06,95 \% \mathrm{CI}=$ 1.04-20.29). However, no significant association was found between miR-149 rs11614913 genetic polymorphism and risk of classic Kaposi sarcoma.

Genetics and Molecular Research 15 (4): gmr15048855 


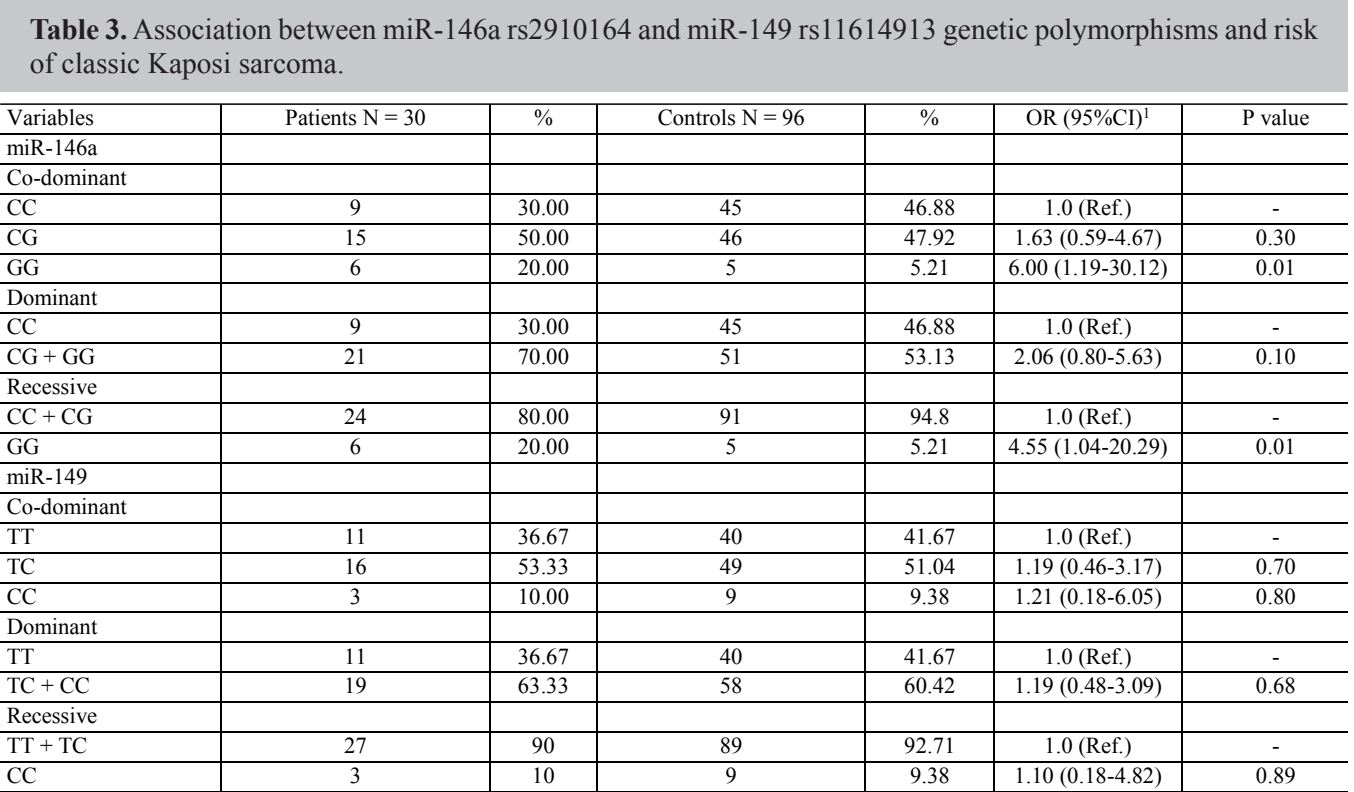

${ }^{1}$ Adjusted for gender and age.

\section{DISCUSSION}

In the present study, we recruited 30 classic Kaposi sarcoma patients and 96 controls in the Xinjiang population of China, and found that the GG genotype of miR-146a was associated with increased risk to classic Kaposi sarcoma.

miRNA is associated with the pathogenesis of various diseases through cell differentiation, tumor growth, and angiogenesis. miR-146a is located on 5q34, and previous studies have reported that expression of miR-146a was associated with the development of several kinds of cancers (Chen et al., 2015b; Shi et al., 2015; Qi et al., 2015; Cui et al., 2016; Sasaki et al., 2016). rs2910164 is located on the negative chain sequence of pre-miR-146a, and this SNP may cause the conversion of G:U to C:U in the neck section of the pre-miRNA-146a hairpin, which could affect the expression and function of miR-146a.

Previous studies have reported that miR-146a polymorphism was associated with the development of several types of cancers (Deng et al., 2015; Yin et al., 2016). In a study with 159 bladder cancer patients, Deng et al. (2015) demonstrated that miRNA146a rs2910164 $\mathrm{C}>\mathrm{G}$ could affect clinical stages and metastasis of this disease. Furthermore, Yin et al. (2016) reported that miRNA146a rs2910164 may influence genetic susceptibility to lung cancer in Chinese smokers. However, some studies were unable to find any association between miR146a polymorphism and risk of cancers (Chen et al., 2015a; Ji et al., 2015; Zhang et al., 2015; Hashemi et al., 2016; Xia et al., 2016). For example, in a meta-analysis composed of 2766 patients with head and neck cancer and 6603 healthy controls, Chen et al. (2015a) reported that miR-146a rs2910164 $\mathrm{C}>\mathrm{G}$ polymorphism was not associated with this type of cancer. Similarly, Zhang et al. (2015) performed a meta-analysis with six studies, and reported that no significant association was found between rs2910164 and rs11614913 polymorphisms and risk 
of gastric cancer. Another meta-analysis with six case-control studies also indicated that no correlation was found between miR-146a rs2910164 polymorphism and the risk of esophageal cancer (Ji et al., 2015). Our study, for the first time, showed a significant association between miR-146a polymorphism and risk of classic Kaposi sarcoma. However, these results need to be further confirmed in large-scale studies.

One limitation should be considered in this study. Due to the low morbidity rate of classic Kaposi sarcoma, our study sample size was small. This may reduce the statistical power of our analysis and lead to discrepancies between the observed results and true values. However, the genetic distributions of miR-146a and miR-149 were in line with HWE, which indicated adequate genetic representation of study subjects.

In conclusion, our study found that miR-146a, but not miR-149 polymorphism, is associated with risk of classic Kaposi sarcoma in the Chinese population. Further investigations via large-scale studies are required to confirm our results.

\section{Conflicts of interest}

The authors declare no conflict of interest.

\section{ACKNOWLEDGMENTS}

We would like to acknowledge the Natural Science Foundation of China (\#81260311) and the People’s Hospital of Xinjiang Uygur Autonomous Region (\#20150115) for their support.

\section{REFERENCES}

Chen XJ, Zhou TY, Chen M, Li N, et al. (2015a). Association of the miRNA146a rs2910164 C >G polymorphism with head and neck cancer risk: a meta-analysis. Asian Pac. J. Cancer Prev. 16: 3871-3874. http://dx.doi.org/10.7314/ APJCP.2015.16.9.3871

Chen ZF, Ma LL and Xue HB (2015b). Common polymorphisms of the microRNA genes (miR-146a and miR-196a-2) and gastric cancer risk: an updated meta-analysis. Genet. Mol. Res. 14: 8589-8601. http://dx.doi.org/10.4238/2015. July. 31.7

Cui Y, She K, Tian D, Zhang P, et al. (2016). miR-146a inhibits proliferation and enhances chemosensitivity in epithelial ovarian cancer via reduction of SOD2. Oncol. Res. 23: 275-282. http://dx.doi.org/10.3727/09650401 $\underline{6 X 14562725373798}$

Deng S, Wang W, Li X and Zhang P (2015). Common genetic polymorphisms in pre-microRNAs and risk of bladder cancer. World J. Surg. Oncol. 13: 297. http://dx.doi.org/10.1186/s12957-015-0683-6

Friedman-Birnbaum R, Bergman R, Bitterman-Deutsch O, Weltfriend S, et al. (1993). Classic and iatrogenic Kaposi's sarcoma. Histopathological patterns as related to clinical course. Am. J. Dermatopathol. 15: 523-527.http://dx.doi. org $/ 10.1097 / 00000372-199312000-00001$

Gazouli M, Zavos G, Papaconstantinou I, Lukas JC, et al. (2004). The interleukin-6-174 promoter polymorphism is associated with a risk of development of Kaposi's sarcoma in renal transplant recipients. Anticancer Res. 24 (2C): 1311-1314.

Gessain A and Duprez R (2005). Spindle cells and their role in Kaposi's sarcoma. Int. J. Biochem. Cell Biol. 37: 24572465.http://dx.doi.org/10.1016/j.biocel.2005.01.018

Guttman-Yassky E, Bar-Chana M, Yukelson A, Linn S, et al. (2003). Epidemiology of classic Kaposi's sarcoma in the Israeli Jewish population between 1960 and 1998. Br. J. Cancer 89: 1657-1660. http://dx.doi.org/10.1038/ sj.bjc. 6601313

Hashemi M, Moradi N, Ziaee SA, Narouie B, et al. (2016). Association between single nucleotide polymorphism in miR499, miR-196a2, miR-146a and miR-149 and prostate cancer risk in a sample of Iranian population. J. Adv. Res. 7: 491-498.http://dx.doi.org/10.1016/j.jare.2016.03.008

Genetics and Molecular Research 15 (4): gmr15048855 
Ji HH, Hong-Luo, Huang GL, Yin HX, et al. (2015). Association between microRNA-196a2 rs11614913, microRNA146a rs2910164, and microRNA-423 rs6505162 polymorphisms and esophageal cancer risk: A meta-analysis. Meta Gene 3: 14-25.http://dx.doi.org/10.1016/j.mgene.2014.12.001

Laresche C, Fournier E, Dupond AS, Woronoff AS, et al. (2014). Kaposi's sarcoma: a population-based cancer registry descriptive study of 57 consecutive cases diagnosed between 1977 and 2009. Int. J. Dermatol. 53: e549-e554. http:// dx.doi.org/10.1111/ijd.12453

Macfarlane LA and Murphy PR (2010). MicroRNA: biogenesis, function and role in cancer. Curr. Genomics 11: 537-561. http://dx.doi.org/10.2174/138920210793175895

Ouyang X, Zeng Y, Fu B, Wang X, et al. (2014). Genotypic analysis of Kaposi's sarcoma-associated herpesvirus from patients with Kaposi's sarcoma in Xinjiang, China. Viruses 6: 4800-4810. http://dx.doi.org/10.3390/v6124800

Qi P, Wang L, Zhou B, Yao WJ, et al. (2015). Associations of miRNA polymorphisms and expression levels with breast cancer risk in the Chinese population. Genet. Mol. Res. 14: 6289-6296. http://dx.doi.org/10.4238/2015.June.11.2

Sasaki H, Yoshiike M, Nozawa S, Usuba W, et al. (2016). Expression level of urinary microRNA-146a-5p is increased in patients with bladder cancer and decreased in those after transurethral resection. Clin. Genitourin. Cancer [Epub ahead of print].

Shi Z, Johnson JJ, Jiang R, Liu Y, et al. (2015). Decrease of miR-146a is associated with the aggressiveness of human oral squamous cell carcinoma. Arch. Oral Biol. 60: 1416-1427. http://dx.doi.org/10.1016/j.archoralbio.2015.06.007

Stiller CA, Trama A, Brewster DH, Verne J, et al.; RARECARE Working Group (2014). Descriptive epidemiology of Kaposi sarcoma in Europe. Report from the RARECARE project. Cancer Epidemiol. 38: 670-678. http://dx.doi. org/10.1016/j.canep.2014.09.009

van der Kuyl AC, Polstra AM, Weverling GJ, Zorgdrager F, et al. (2004). An IL-8 gene promoter polymorphism is associated with the risk of the development of AIDS-related Kaposi's sarcoma: a case-control study. AIDS 18: 12061208. http://dx.doi.org/10.1097/00002030-200405210-00016

Wu XJ, Pu XM, Zhao ZF, Zhao YN, et al. (2015). The expression profiles of microRNAs in Kaposi's sarcoma. Tumour Biol. 36: 437-446. http://dx.doi.org/10.1007/s13277-014-2626-1

Xia ZG, Yin HF, Long Y, Cheng L, et al. (2016). Genetic variant of miR-146a rs2910164 C $>\mathrm{G}$ and gastric cancer susceptibility. Oncotarget [Epub ahead of print].

Yin Z, Cui Z, Ren Y, Xia L, et al. (2016). Association between polymorphisms in pre-miRNA genes and risk of lung cancer in a Chinese non-smoking female population. Lung Cancer 94: 15-21. http://dx.doi.org/10.1016/j. lungcan.2016.01.013

Zhang L, Gao J, Zhou D and Bao F (2015). Lack of association of two common polymorphisms rs2910164 and rs11614913 with susceptibility to gastric cancer: A meta-analysis. Turk. J. Gastroenterol. 26: 378-385.http://dx.doi.org/10.5152/ tig. 2015.6603

Genetics and Molecular Research 15 (4): gmr15048855 